\title{
Design Robust Fuzzy Sliding Mode Control Technique for Robot Manipulator Systems with Modeling Uncertainties
}

\author{
Farzin Piltan \\ Industrial Electrical and Electronic Engineering SanatkadeheSabze Pasargad. CO (S.S.P. Co), NO:16, PO.Code 71347- \\ 66773, Fourth floor, Dena Apr, Seven Tir Ave, Shiraz, Iran \\ E-mail:SSP.ROBOTIC@gmail.com
}

\begin{abstract}
AliReza Nabaee
Industrial Electrical and Electronic Engineering SanatkadeheSabze Pasargad. CO (S.S.P. Co), NO:16, PO.Code 7134766773, Fourth floor, Dena Apr, Seven Tir Ave, Shiraz, Iran E-mail:SSP.ROBOTIC@yahoo.com

MohammadMahdi Ebrahimi

Industrial Electrical and Electronic Engineering SanatkadeheSabze Pasargad. CO (S.S.P. Co), NO:16, PO.Code 7134766773, Fourth floor, Dena Apr , Seven Tir Ave, Shiraz , Iran

E-mail:SSP.ROBOTIC@yahoo.com

Mansour Bazregar

Industrial Electrical and Electronic Engineering SanatkadeheSabze Pasargad. CO (S.S.P. Co), NO:16, PO.Code 7134766773, Fourth floor, Dena Apr, Seven Tir Ave, Shiraz, Iran

E-mail:SSP.ROBOTIC@yahoo.com
\end{abstract}

\begin{abstract}
This paper describes the design and implementation of robust nonlinear sliding mode control strategies for robot manipulators whose dynamic or kinematic models are uncertain. Therefore a fuzzy sliding mode tracking controller for robot manipulators with uncertainty in the kinematic and dynamic models is design and analyzes. The controller is developed based on the unit quaternion representation so that singularities associated with the otherwise commonly used three parameter representations are avoided. Simulation results for a planar application of the continuum or hyper-redundant robot manipulator (CRM) are provided to illustrate the performance of the developed adaptive controller. These manipulators do not have rigid joints, hence, they are difficult to model and this leads to significant challenges in developing high-performance control algorithms. In this research, a joint level controller for continuum robots is described which utilizes a fuzzy methodology component to compensate for dynamic uncertainties.
\end{abstract}

Index Terms - Sliding Mode Control, Fuzzy Logic Methodology, Robust Controller, Hyper-Redundant, Continuum Robot Manipulator

\section{Introduction}

Continuum robots represent a class of robots that have a biologically inspired form characterized by flexible backbones and high degrees-of-freedom structures [1]. The idea of creating "trunk and tentacle" robots, (in recent years termed continuum robots [1]), is not new [2]. Inspired by the bodies of animals such as snakes [3], the arms of octopi [4], and the trunks of elephants [5], [6], researchers have been building prototypes for many years. A key motivation in this research has been to reproduce in robots some of the special qualities of the biological counterparts. This includes the ability to "slither" into tight and congested spaces, and (of particular interest in this work) the ability to grasp and manipulate a wide range of objects, via the use of "whole arm manipulation" i.e. wrapping their bodies around objects, conforming to their shape profiles. Hence, these robots have potential applications in whole arm grasping and manipulation in unstructured environments such as rescue operations. Theoretically, the compliant nature of a continuum robot provides infinite degrees of freedom to these devices. However, there is a limitation set by the practical inability to incorporate infinite actuators in the device. Most of these robots are consequently underactuated (in terms of numbers of independent actuators) with respect to their anticipated tasks. In other words they must achieve a 
wide range of configurations with relatively few control inputs. This is partly due to the desire to keep the body structures (which, unlike in conventional rigid-link manipulators or fingers, are required to directly contact the environment) "clean and soft", but also to exploit the extra control authority available due to the continuum contact conditions with a minimum number of actuators. For example, the Octarm VI continuum manipulator, discussed frequently in this paper, has nine independent actuated degrees-of-freedom with only three sections. Continuum manipulators differ fundamentally from rigid-link and hyper-redundant robots by having an unconventional structure that lacks links and joints. Hence, standard techniques like the Denavit-Hartenberg (D-H) algorithm cannot be directly applied for developing continuum arm kinematics. Moreover, the design of each continuum arm varies with respect to the flexible backbone present in the system, the positioning, type and number of actuators. The constraints imposed by these factors make the set of reachable configurations and nature of movements unique to every continuum robot. This makes it difficult to formulate generalized kinematic or dynamic models for continuum robot hardware. Chirikjian and Burdick were the first to introduce a method for modeling the kinematics of a continuum structure by representing the curve-shaping function using modal functions [6]. Mochiyama used the Serret- Frenet formulae to develop kinematics of hyper-degrees of freedom continuum manipulators [5]. For details on the previously developed and more manipulator-specific kinematics of the Rice/Clemson "Elephant trunk" manipulator, see [1] [2], [5]. For the Air Octor and Octarm continuum robots, more general forward and inverse kinematics have been developed by incorporating the transformations of each section of the manipulator (using D-H parameters of an equivalent virtual rigid link robot) and expressing those in terms of the continuum manipulator section parameters [4]. The net result of the work in [6], [3]-[5] is the establishment of a general set of kinematic algorithms for continuum robots. Thus, the kinematics (i.e. geometry based modeling) of a quite general set of prototypes of continuum manipulators has been developed and basic control strategies now exist based on these. The development of analytical models to analyze continuum arm dynamics (i.e. physicsbased models involving forces in addition to geometry) is an active, ongoing research topic in this field. From a practical perspective, the modeling approaches currently available in the literature prove to be very complicated and a dynamic model which could be conveniently implemented in an actual device's realtime controller has not been developed yet. The absence of a computationally tractable dynamic model for these robots also prevents the study of interaction of external forces and the impact of collisions on these continuum structures. This impedes the study and ultimate usage of continuum robots in various practical applications like grasping and manipulation, where impulsive dynamics [1], [4] are important factors. Although continuum robotics is an interesting subclass of robotics with promising applications for the future, from the current state of the literature, this field is still in its stages of inception.

Controller is a device which can sense information from linear or nonlinear system (e.g., continuum robot) to improve the systems performance [7-20]. The main targets in designing control systems are stability, good disturbance rejection, and small tracking error[7, 21-30] Several continuum robot are controlled by linear methodologies (e.g., Proportional-Derivative (PD) controller, Proportional- Integral (PI) controller or Proportional- Integral-Derivative (PID) controller), but when robot works with various payloads and have uncertainty in dynamic models this technique has limitations. In some applications continuum robot are used in an unknown and unstructured environment, therefore strong mathematical tools used in new control methodologies to design nonlinear robust controller with an acceptable performance (e.g., minimum error, good trajectory, disturbance rejection) [31-45].

Sliding mode controller is an influential nonlinear controller to certain and uncertain systems which it is based on system's dynamic model. Sliding mode controller is a powerful nonlinear robust controller under condition of partly uncertain dynamic parameters of system [7, 40-57]. This controller is used to control of highly nonlinear systems especially for continuum robot. Chattering phenomenon and nonlinear equivalent dynamic formulation in uncertain dynamic parameter are two main drawbacks in pure sliding mode controller [20, 46-57]. The chattering phenomenon problem in pure sliding mode controller is reduced by using linear saturation boundary layer function but prove the stability is very difficult.

Gradient descent is a first-order optimization algorithm. Gradient descent works in spaces of any number of dimensions, even in infinite-dimensional ones. In the latter case the search space is typically a function space, and one calculates the Gâteaux derivative of the functional to be minimized to determine the descent direction. The gradient descent can take much iteration to compute a local minimum with a required accuracy, if the curvature in different directions is very different for the given function. This method is based on resolve the sliding surface slope as well as improve the output performance by Gradient Descent Optimal Algorithm (GDOA) tuning the sliding surface slope coefficient. The sliding surface gain $(\boldsymbol{\lambda})$ of this controller is adjusted off line depending on the iterations.

Although the fuzzy-logic control is not a new technique, its application in this current research is considered to be novel since it aimed for an automated dynamic-less response rather than for the traditional objective of uncertainties compensation[38]. The intelligent tracking control using the fuzzy-logic technique provides a cost-and-time efficient control 
implementation due to the automated dynamic-less input. This in turn would further inspire multiuncertainties testing for continuum robot [38].

This paper is organized as follows; section 2, is served as an introduction to the sliding mode controller formulation algorithm and its application to control of continuum robot, dynamic of continuum robot and proof of stability. Part 3, introduces and describes the methodology (gradient descent optimal sliding mode controller) algorithm. Section 4 presents the simulation results and discussion of this algorithm applied to a continuum robot and the final section describe the conclusion.

\section{Theory}

\subsection{Dynamic Formulation of Continuum Robot}

The Continuum section analytical model developed here consists of three modules stacked together in series. In general, the model will be a more precise replication of the behavior of a continuum arm with a greater of modules included in series. However, we will show that three modules effectively represent the dynamic behavior of the hardware, so more complex models are not motivated. Thus, the constant curvature bend exhibited by the section is incorporated inherently within the model. The mass of the arm is modeled as being concentrated at three points whose co-ordinates referenced with respect to (see Figure 1);

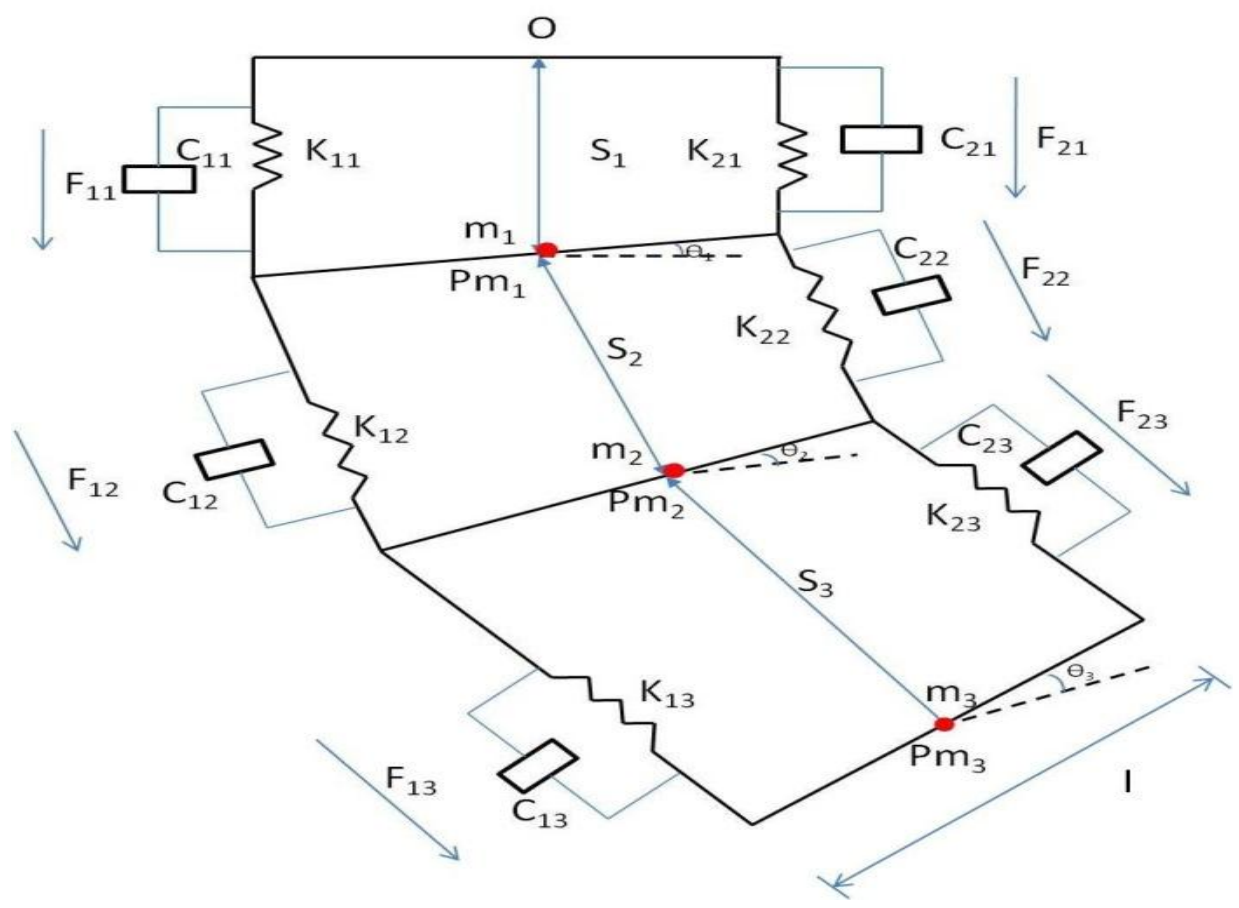

Fig. 1: Assumed structure for analytical model of a section of a continuum arm

\section{Where;}

$l$ - Length of the rigid rod connecting the two struts, constant throughout the structure,

$k_{1, i}, i=1,2,3$ - Spring constant of actuator 1 at module $i$,

$k_{2, i}, i=1,2,3$ - Spring constant of actuator 2 at module $i$,

$C_{1, i}, i=1,2,3$ - Damping coefficient of actuator 1 at module $i$,

$C_{2, i}, i=1,2,3$ - Damping coefficient of actuator 2 at module $i$,

$m_{i}, i=1,2,3$ - Mass in each module,

$I_{i}, i=1,2,3$ - Moment of inertia of the rigid rod in each module.
A global inertial frame $(\mathrm{N})$ located at the base of the arm are given below

$$
\begin{aligned}
& { }_{m 1}^{N P}=S_{1} \cdot \widehat{n_{3}} \\
& { }_{m 2}^{N} P=S_{2} \cdot \sin \theta_{1} \widehat{n_{1}}+\left(S_{1}+S_{2} \cos \theta_{1}\right) \cdot \widehat{n_{3}} \\
& \underset{{ }_{3} P}{N}=\left(S_{2} \cdot \sin \theta_{1}+S_{3} \cdot \sin \left(\theta_{1}+\right.\right. \\
& \left.\left.\theta_{2}\right)\right) \widehat{n_{1}}+\left(S_{1}+S_{2} \cos \theta_{1}+S_{3} \cdot \cos \left(\theta_{1}+\right.\right. \\
& \left.\left.\left.\theta_{2}\right)\right)\right) \cdot \widehat{n_{3}}
\end{aligned}
$$

The position vector of each mass is initially defined in a frame local to the module in which it is present. These local frames are located at the base of each module and oriented along the direction of variation of coordinate ' $s$ ' of that module. The positioning of each of these masses is at the centre of mass of the rigid rods 
connecting the two actuators. Differentiating the position vectors we obtain the linear velocities of the masses. The kinetic energy (T) of the system comprises the sum of linear kinetic energy terms (constructed using the above velocities) and rotational kinetic energy terms due to rotation of the rigid rod connecting the two actuators, and is given below as

$$
\begin{aligned}
& T=(0.5) m_{1} \dot{s}_{1}{ }^{2}+(0.5) m_{2}\left(\left(\dot{s}_{2} \sin \theta_{1}+\right.\right. \\
& \left.s_{2} \cos \theta_{1} \dot{\theta}_{1}\right)^{2}+\left(\dot{s}_{1}+\dot{s}_{2} \cos \theta_{1}-\right. \\
& \left.\left.s_{2} \sin \theta_{1} \dot{\theta}_{1}\right)^{2}\right)+(0.5) m_{3}\left(\left(\dot{s}_{2} \sin \theta_{1}+\right.\right. \\
& s_{2} \cos \theta_{1} \dot{\theta}_{1}+\dot{s}_{3} \sin \left(\theta_{1}+\theta_{2}\right)+ \\
& \left.s_{3} \cos \left(\theta_{1}+\theta_{2}\right) \dot{\theta}_{1}+s_{3} \cos \left(\theta_{1}+\theta_{2}\right) \dot{\theta}_{2}\right)^{2}+ \\
& \left(\dot{s}_{1}+\dot{s}_{2} \cos \theta_{1}-s_{2} \sin \theta_{1} \dot{\theta}_{1}+\dot{s}_{3} \cos \left(\theta_{1}+\right.\right. \\
& \left.\theta_{2}\right)-s_{3} \sin \left(\theta_{1}+\theta_{2}\right) \dot{\theta}_{1}-s_{3} \sin \left(\theta_{1}+\right. \\
& \left.\left.\left.\theta_{2}\right) \dot{\theta}_{2}\right)^{2}\right)+(0.5) I_{1} \dot{\theta}_{1}{ }^{2}+(0.5) I_{2}\left(\dot{\theta}_{1}{ }^{2}+\right. \\
& \left.\dot{\theta}_{2}{ }^{2}\right)+(0.5) I_{3}\left(\dot{\theta}_{1}{ }^{2}+\dot{\theta}_{2}{ }^{2}+\dot{\theta}_{3}{ }^{2}\right) .
\end{aligned}
$$

The potential energy $(\mathrm{P})$ of the system comprises the sum of the gravitational potential energy and the spring potential energy. A small angle assumption is made throughout the derivation. This allows us to directly express the displacement of springs and the velocities associated with dampers in terms of system generalized coordinates.

$$
\begin{aligned}
& P=-m_{1} g s_{1}-m_{2} g\left(s_{1}+s_{2} \cos \theta_{1}\right)- \\
& m_{3} g\left(s_{1}+s_{2} \cos \theta_{1}+s_{3} \cos \left(\theta_{1}+\theta_{1}\right)\right)+ \\
& (0.5) k_{11}\left(s_{1}+(1 / 2) \theta_{1}-s_{01}\right)^{2}+ \\
& (0.5) k_{21}\left(s_{1}+(1 / 2) \theta_{1}-s_{01}\right)^{2}+ \\
& (0.5) k_{12}\left(s_{2}+(1 / 2) \theta_{2}-s_{02}\right)^{2}+ \\
& (0.5) k_{22}\left(s_{2}+(1 / 2) \theta_{2}-s_{02}\right)^{2}+ \\
& (0.5) k_{13}\left(s_{3}+(1 / 2) \theta_{3}-s_{03}\right)^{2}+ \\
& (0.5) k_{23}\left(s_{3}+(1 / 2) \theta_{3}-s_{03}\right)^{2}
\end{aligned}
$$

where, $S_{01}, S_{02}, S_{03}$ are the initial values of $S_{1}, S_{2}, S_{3}$ respectively.

Due to viscous damping in the system, Rayliegh's dissipation function [6] is used to give damping energy

$$
\begin{aligned}
& D=(0.5) c_{11}\left(\dot{s}_{1}+(1 / 2) \dot{\theta}_{1}\right)^{2}+ \\
& (0.5) c_{21}\left(\dot{s}_{1}+(1 / 2) \dot{\theta}_{1}\right)^{2}+(0.5) c_{12}\left(\dot{s}_{2}+\right. \\
& \left.(1 / 2) \dot{\theta}_{2}\right)^{2}+(0.5) c_{22}\left(\dot{s}_{2}+(1 / 2) \dot{\theta}_{2}\right)^{2}+ \\
& (0.5) c_{13}\left(\dot{s}_{3}+(1 / 2) \dot{\theta}_{3}\right)^{2}+(0.5) c_{23}\left(\dot{s}_{3}+\right. \\
& \left.(1 / 2) \dot{\theta}_{3}\right)^{2}
\end{aligned}
$$

The generalized forces in the system corresponding to the generalized co-ordinates are expressed as appropriately weighted combinations of the input forces.

$$
\begin{aligned}
& Q_{s_{1}}=F_{11}+F_{21}+\left(F_{12}+F_{22}\right) \cos \theta_{1}+ \\
& \left(F_{13}+F_{23}\right) \cos \left(\theta_{1}+\theta_{2}\right) \\
& Q_{s_{2}}=F_{12}+F_{22}+\left(F_{13}+F_{23}\right) \cos \left(\theta_{2}\right) \\
& Q_{s_{3}}=F_{13}+F_{23} \\
& Q_{\theta_{1}}=(1 / 2)\left(F_{11}-F_{21}\right)+(1 / 2)\left(F_{12}-\right. \\
& \left.F_{22}\right)+(1 / 2)\left(F_{13}-F_{23}\right)+ \\
& s_{2} \sin \theta_{2}\left(F_{13}+F_{23}\right) \\
& Q_{\theta_{1}}=(1 / 2)\left(F_{12}-F_{22}\right) \\
& \quad+(1 / 2)\left(F_{13}-F_{23}\right) \\
& Q_{\theta_{1}}=(1 / 2)\left(F_{13}-F_{23}\right)
\end{aligned}
$$

It can be evinced from the force expressions that the total input forces acting on each module can be resolved into an additive component along the direction of extension and a subtractive component that results in a torque. For the first module, there is an additional torque produced by forces in the third module.

The model resulting from the application of Lagrange's equations of motion obtained for this system can be represented in the form

$$
F_{\text {coeff } \underline{\tau}}=D(\underline{q}) \underline{\ddot{q}}+C(\underline{q}) \underline{\dot{q}}+G(\underline{q})
$$

where $\tau$ is a vector of input forces and $\mathrm{q}$ is a vector of generalized co-ordinates. The force coefficient matrix $F_{\text {coeff }}$ transforms the input forces to the generalized forces and torques in the system. The inertia matrix, $D$ is composed of four block matrices. The block matrices that correspond to pure linear accelerations and pure angular accelerations in the system (on the top left and on the bottom right) are symmetric. The matrix $C$ contains coefficients of the first order derivatives of the generalized co-ordinates. Since the system is nonlinear, many elements of $C$ contain first order derivatives of the generalized co-ordinates. The remaining terms in the dynamic equations resulting from gravitational potential energies and spring energies are collected in the matrix $G$. The coefficient matrices of the dynamic equations are given below,

$$
\text { Fcoeff }=\left[\begin{array}{cccccc}
1 & 1 & \cos \left(\theta_{1}\right) & \cos \left(\theta_{1}\right) & \cos \left(\theta_{1}+\theta_{2}\right) & \cos \left(\theta_{1}+\theta_{2}\right) \\
0 & 0 & 1 & 1 & \cos \left(\theta_{2}\right) & \cos \left(\theta_{2}\right) \\
0 & 0 & 0 & 0 & 1 & 1 \\
1 / 2 & -1 / 2 & 1 / 2 & -1 / 2 & 1 / 2+s_{2} \sin \left(\theta_{2}\right) & -1 / 2+s_{2} \sin \left(\theta_{2}\right) \\
0 & 0 & 1 / 2 & -1 / 2 & 1 / 2 & -1 / 2 \\
0 & 0 & 0 & 0 & 1 / 2 & -1 / 2
\end{array}\right]
$$


Design Robust Fuzzy Sliding Mode Control Technique

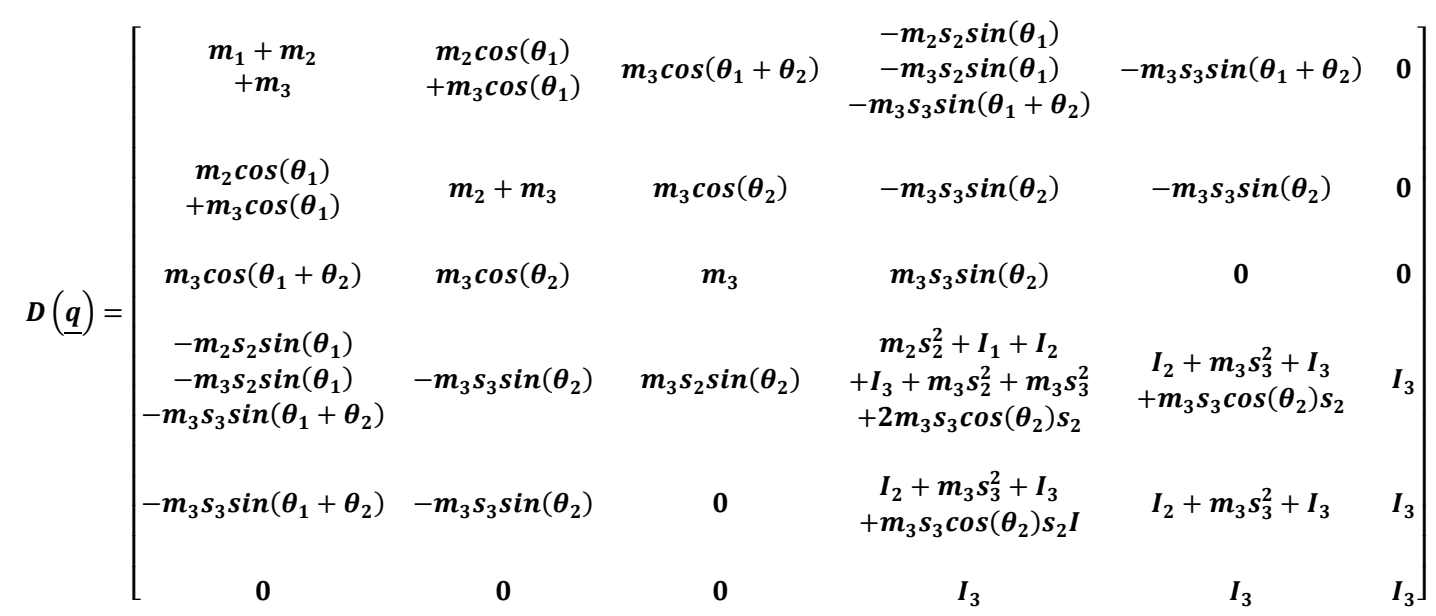

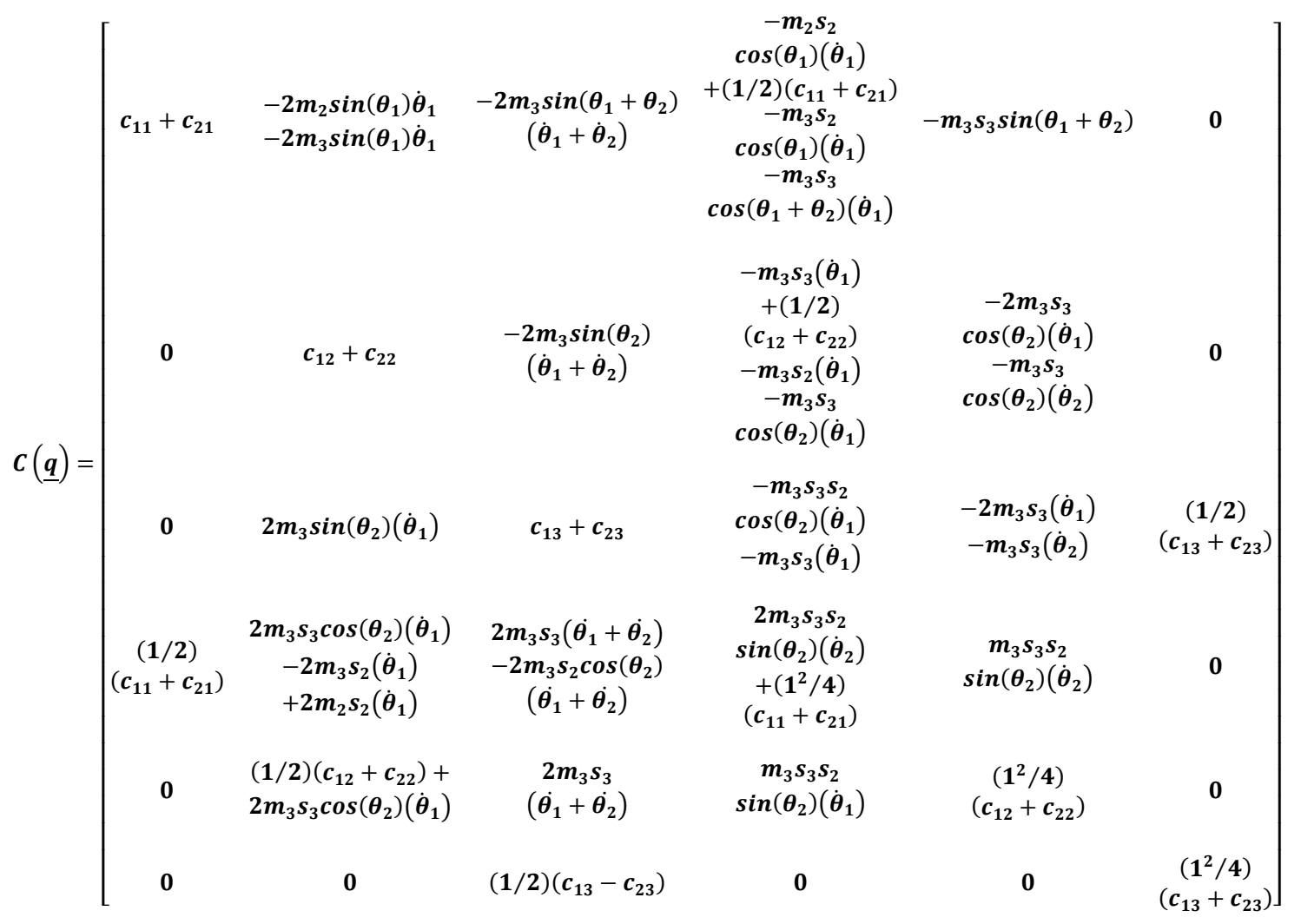

$$
G(\underline{q})=\left[\begin{array}{c}
-m_{1} g-m_{2} g+k_{11}\left(s_{1}+(1 / 2) \theta_{1}-s_{01}\right)+k_{21}\left(s_{1}-(1 / 2) \theta_{1}-s_{01}\right)-m_{3} g \\
-m_{2} g \cos \left(\theta_{1}\right)+k_{12}\left(s_{2}+(1 / 2) \theta_{2}-s_{02}\right)+k_{22}\left(s_{2}-(1 / 2) \theta_{2}-s_{02}\right)-m_{3} g \cos \left(\theta_{1}\right) \\
-m_{3} g \cos \left(\theta_{1}+\theta_{2}\right)+k_{13}\left(s_{3}+(1 / 2) \theta_{3}-s_{03}\right)+k_{23}\left(s_{3}-(1 / 2) \theta_{3}-s_{03}\right) \\
m_{2} s_{2} g \sin \left(\theta_{1}\right)+m_{3} s_{3} g \sin \left(\theta_{1}+\theta_{2}\right)+m_{3} s_{2} g \sin \left(\theta_{1}\right)+k_{11}\left(s_{1}+(1 / 2) \theta_{1}-s_{01}\right)(1 / 2) \\
+k_{21}\left(s_{1}-(1 / 2) \theta_{1}-s_{01}\right)(-1 / 2) \\
m_{3} s_{3} g \sin \left(\theta_{1}+\theta_{2}\right)+k_{12}\left(s_{2}+(1 / 2) \theta_{2}-s_{02}\right)(1 / 2)+k_{22}\left(s_{2}-(1 / 2) \theta_{2}-s_{02}\right)(-1 / 2) \\
k_{13}\left(s_{3}+(1 / 2) \theta_{3}-s_{03}\right)(1 / 2)+k_{23}\left(s_{3}-(1 / 2) \theta_{3}-s_{03}\right)(-1 / 2)
\end{array}\right]
$$

\subsection{Sliding Mode Controller}

Consider a nonlinear single input dynamic system is

$$
x^{(n)}=f(\vec{x})+b(\vec{x}) u
$$
defined by [6]: 
Where $\mathrm{u}$ is the vector of control input, $\boldsymbol{x}^{(\boldsymbol{n})}$ is the $\boldsymbol{n}^{\boldsymbol{t h}}$ derivation of $x, x=\left[x, \dot{x}, \ddot{x}, \ldots, x^{(n-1)}\right]^{T}$ is the state vector, $\boldsymbol{f}(\boldsymbol{x})$ is unknown or uncertainty, and $\boldsymbol{b}(\boldsymbol{x})$ is of known sign function. The main goal to design this controller is train to the desired state; $\boldsymbol{x}_{\boldsymbol{d}}=$ $\left[x_{d}, \dot{x}_{d}, \ddot{x}_{d}, \ldots, x_{d}^{(n-1)}\right]^{T}$, and trucking error vector is defined by [6]:

$$
\widetilde{x}=x-x_{d}=\left[\widetilde{x}, \ldots, \widetilde{x}^{(n-1)}\right]^{T}
$$

A time-varying sliding surface $\boldsymbol{s}(\boldsymbol{x}, \boldsymbol{t})$ in the state space $\boldsymbol{R}^{\boldsymbol{n}}$ is given by [6]:

$$
s(x, t)=\left(\frac{d}{d t}+\lambda\right)^{n-1} \tilde{x}=0
$$

where $\lambda$ is the positive constant. To further penalize tracking error, integral part can be used in sliding surface part as follows [6]:

$$
\boldsymbol{s}(\boldsymbol{x}, \boldsymbol{t})=\left(\frac{d}{d t}+\lambda\right)^{n-1}\left(\int_{0}^{t} \tilde{\boldsymbol{x}} \boldsymbol{d t}\right)=\mathbf{0}
$$

The main target in this methodology is kept the sliding surface slope $\boldsymbol{s}(\boldsymbol{x}, \boldsymbol{t})$ near to the zero. Therefore, one of the common strategies is to find input $\boldsymbol{U}$ outside of $\boldsymbol{s}(\boldsymbol{x}, \boldsymbol{t})$ [6].

$$
\frac{1}{2} \frac{d}{d t} s^{2}(x, t) \leq-\zeta|s(x, t)|
$$

where $\zeta$ is positive constant.

$$
\text { If } \mathbf{S}(\mathbf{0})>\mathbf{0} \rightarrow \frac{\mathrm{d}}{\mathrm{dt}} \mathbf{S}(\mathbf{t}) \leq-\zeta
$$

To eliminate the derivative term, it is used an integral term from $\mathrm{t}=0$ to $\mathrm{t}=\boldsymbol{t}_{\text {reach }}$

$$
\begin{gathered}
\int_{t=0}^{t=t_{\text {reach }}} \frac{d}{d t} S(t) \leq-\int_{t=0}^{t=t_{\text {reach }}} \eta \rightarrow \\
S\left(t_{\text {reach }}\right)-S(0) \leq-\zeta\left(t_{\text {reach }}-0\right)
\end{gathered}
$$

Where $t_{\text {reach }}$ is the time that trajectories reach to the sliding surface so, suppose $\mathrm{S}\left(t_{\text {reach }}=0\right)$ defined as;

$$
0-S(0) \leq-\eta\left(t_{\text {reach }}\right) \rightarrow t_{\text {reach }} \leq \frac{S(0)}{\zeta}
$$

and

$$
\begin{gathered}
\text { if } \boldsymbol{S}(\mathbf{0})<0 \rightarrow 0-S(0) \leq-\eta\left(\boldsymbol{t}_{\text {reach }}\right) \rightarrow \\
\boldsymbol{S}(\mathbf{0}) \leq-\zeta\left(\boldsymbol{t}_{\text {reach }}\right) \rightarrow \boldsymbol{t}_{\text {reach }} \leq \frac{|\boldsymbol{S}(\mathbf{0})|}{\eta}
\end{gathered}
$$

Equation (26) guarantees time to reach the sliding surface is smaller than $\frac{|\boldsymbol{S}(\mathbf{0})|}{\zeta}$ since the trajectories are outside of $S(t)$.

$$
\text { if } S_{t_{\text {reach }}}=S(0) \rightarrow \operatorname{error}\left(x-x_{d}\right)=0
$$

$$
\begin{aligned}
& \text { Suppose } S \text { is defined as } \\
& \qquad \boldsymbol{s}(\boldsymbol{x}, \boldsymbol{t})=\left(\frac{d}{d t}+\lambda\right) \quad \tilde{x}=\left(\dot{\mathbf{x}}-\dot{\mathbf{x}}_{\mathbf{d}}\right)+ \\
& \lambda\left(\mathbf{x}-\mathbf{x}_{\mathbf{d}}\right)
\end{aligned}
$$

The derivation of $S$, namely, $\dot{S}$ can be calculated as the following;

$$
\dot{S}=\left(\ddot{\mathbf{x}}-\ddot{\mathbf{x}}_{\mathbf{d}}\right)+\lambda\left(\dot{\mathbf{x}}-\dot{\mathbf{x}}_{\mathbf{d}}\right)
$$

Suppose the second order system is defined as;

$$
\begin{array}{r}
\ddot{x}=f+u \rightarrow \dot{S}=f+U-\ddot{x}_{d} \\
+\lambda\left(\dot{\mathbf{x}}-\dot{\mathbf{x}}_{\mathbf{d}}\right)
\end{array}
$$

Where $\boldsymbol{f}$ is the dynamic uncertain, and also since $S=0$ and $\dot{S}=0$, to have the best approximation , $\widehat{\boldsymbol{U}}$ is defined as

$$
\widehat{\boldsymbol{U}}=-\widehat{\boldsymbol{f}}+\ddot{\boldsymbol{x}}_{\boldsymbol{d}}-\lambda\left(\dot{\mathbf{x}}-\dot{\mathbf{x}}_{\mathbf{d}}\right)
$$

A simple solution to get the sliding condition when the dynamic parameters have uncertainty is the switching control law [52-53]:

$$
U_{d i s}=\widehat{U}-K(\vec{x}, t) \cdot \operatorname{sgn}(s)
$$

where the switching function $\mathbf{s g n}(\mathbf{S})$ is defined as $[1,6]$

$$
\operatorname{sgn}(s)= \begin{cases}1 & s>0 \\ -1 & s<0 \\ 0 & s=0\end{cases}
$$

and the $\boldsymbol{K}(\overrightarrow{\boldsymbol{x}}, \boldsymbol{t})$ is the positive constant. Suppose by (22) the following equation can be written as,

$$
\begin{aligned}
\frac{1}{2} \frac{d}{d t} s^{2}(x, t)=\dot{S} \cdot S & =[f-\hat{f}-K \operatorname{sgn}(s)] \cdot S \\
& =(f-\hat{f}) \cdot S-K|S|
\end{aligned}
$$

and if the equation (26) instead of (25) the sliding surface can be calculated as

$$
\begin{aligned}
& s(x, t)=\left(\frac{d}{d t}+\lambda\right)^{2}\left(\int_{0}^{t} \tilde{x} d t\right)= \\
& \left(\dot{\mathbf{x}}-\dot{\mathbf{x}}_{\mathrm{d}}\right)+2 \lambda\left(\dot{\mathbf{x}}-\dot{\mathbf{x}}_{\mathrm{d}}\right)-\lambda^{2}\left(\mathbf{x}-\mathbf{x}_{\mathrm{d}}\right)
\end{aligned}
$$

in this method the approximation of $\boldsymbol{U}$ is computed as [6]

$$
\begin{aligned}
\widehat{U}=-\widehat{f}+\ddot{x}_{d}- & 2 \lambda\left(\dot{\mathbf{x}}-\dot{\mathbf{x}}_{\mathbf{d}}\right) \\
& +\lambda^{2}\left(\mathbf{x}-\mathbf{x}_{\mathbf{d}}\right)
\end{aligned}
$$

Based on above discussion, the sliding mode control law for a multi degrees of freedom robot manipulator is written as $[1,6]$ :

$$
\tau=\tau_{e q}+\tau_{d i s}
$$


Where, the model-based component $\boldsymbol{\tau}_{\boldsymbol{e q}}$ is the nominal dynamics of systems calculated as follows [1]:

$$
\tau_{e q}=\left[M^{-1}(B+C+G)+\dot{S}\right] M
$$

and $\boldsymbol{\tau}_{\text {dis }}$ is computed as [1];

$$
\tau_{d i s}=K \cdot \operatorname{sgn}(S)
$$

By (39) and (38) the sliding mode control of robot manipulator is calculated as;

$$
\tau=\left[M^{-1}(B+C+G)+\dot{S}\right] M+K \cdot \operatorname{sgn}(S)
$$

where $S=\lambda e+\dot{e}$ in $\mathrm{PD}-\mathrm{SMC}$ and $S=\lambda e+\dot{e}+$ $\left(\frac{\lambda}{2}\right)^{2} \sum e$ in PID-SMC.

\subsubsection{Proof of Stability}

The lyapunov formulation can be written as follows,

$$
V=\frac{1}{2} S^{T} \cdot M \cdot S
$$

The derivation of $V$ can be determined as,

$$
\dot{V}=\frac{1}{2} S^{T} \cdot \dot{M} \cdot S+S^{T} M \dot{S}
$$

The dynamic equation of robot manipulator can be written based on the sliding surface as

$$
M \dot{S}=-V S+M \dot{S}+B+C+G
$$

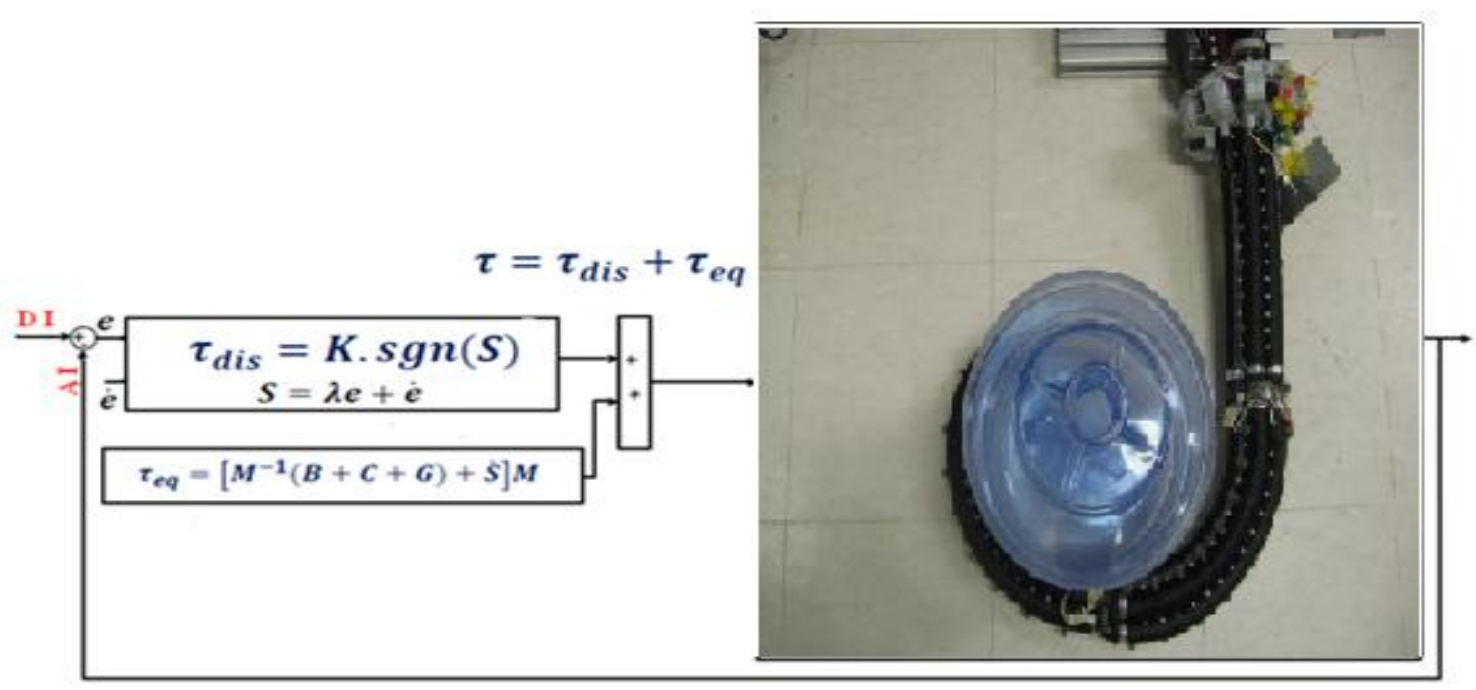

Fig. 2: Sliding Mode Controller

\subsubsection{Fuzzy Logic Methodology}

Based on foundation of fuzzy logic methodology; fuzzy logic controller has played important rule to design nonlinear controller for nonlinear and uncertain
It is assumed that

$$
S^{T}(\dot{M}-2 B+C+G) S=0
$$

by substituting (43) in (44)

$$
\begin{aligned}
& \dot{V}=\frac{1}{2} S^{T} \dot{M} S-S^{T} B+C S+S^{T}(M \dot{S}+B+C S+ \\
& G)=S^{T}(M \dot{S}+B+C S+G)
\end{aligned}
$$

Suppose the control input is written as follows

$$
\begin{aligned}
& \widehat{U}=U_{\text {Nonlinear }}+\widehat{U_{d l s}}=\left[\widehat{M^{-1}}(B+C+G)+\right. \\
& \dot{S}] \widehat{M}+K \cdot \operatorname{sgn}(S)+B+C S+G
\end{aligned}
$$

By replacing the equation (49) in (41)

$$
\begin{aligned}
& \dot{V}=S^{T}(M \dot{S}+B+C+G-\widehat{M} \dot{S}-\widehat{B+C S}+G- \\
& K \operatorname{sgn}(S)=S^{T}(\widetilde{M} \dot{S}+\widehat{B+C} S+G-K \operatorname{sgn}(S))
\end{aligned}
$$
and

$$
|\widetilde{M} \dot{S}+\widetilde{B+C} S+G| \leq|\widetilde{M} \dot{S}|+|\widetilde{B+C} S+G|
$$

The Lemma equation in robot arm system can be written as follows

$$
K_{u}=[|\widetilde{M} \dot{S}|+|B+C S+G|+\eta]_{i}, i=1,2,3,4, \ldots
$$

and finally;

$$
\dot{V} \leq-\sum_{i=1}^{n} \eta_{i}\left|S_{i}\right|
$$

Figure 2 shows the pure sliding mode controller applied to continuum robot. systems [53]. However the application area for fuzzy control is really wide, the basic form for all command types of controllers consists of;

Input fuzzification (binary-to-fuzzy $[\mathrm{B} / \mathrm{F}]$ conversion) 
Fuzzy rule base (knowledge base), Inference engine and Output defuzzification (fuzzy-to-binary [F/B] conversion). Figure 3 shows the fuzzy controller part.

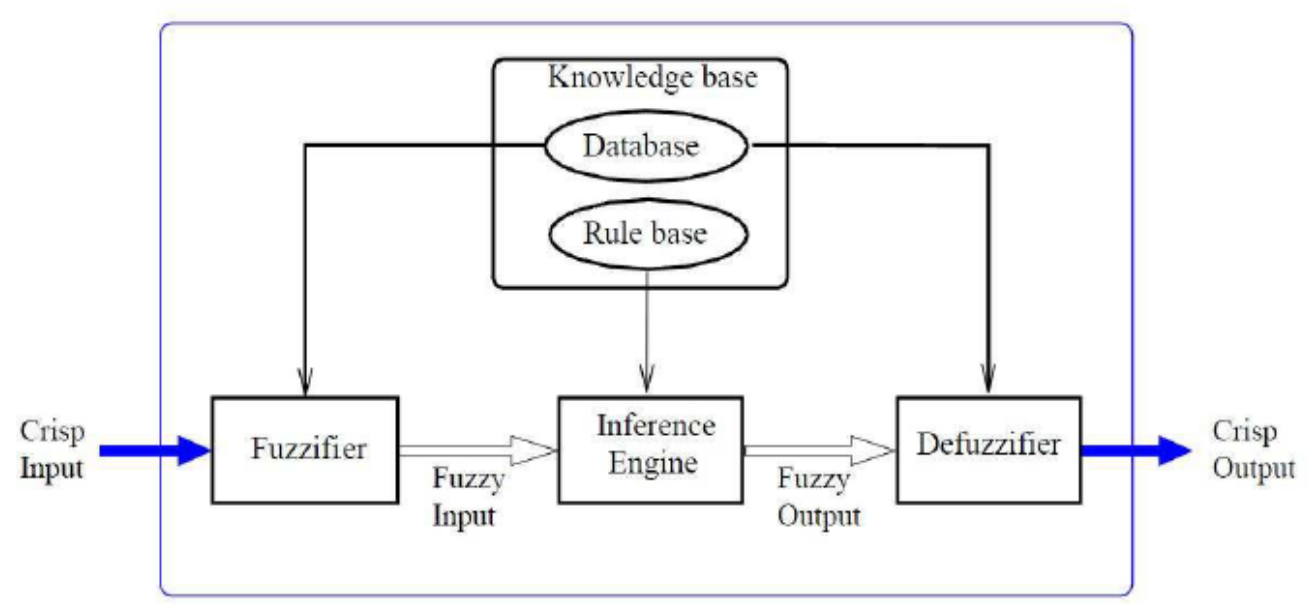

Fig. 3: Fuzzy Controller Part

The fuzzy inference engine offers a mechanism for transferring the rule base in fuzzy set which it is divided into two most important methods, namely, Mamdani method and Sugeno method. Mamdani method is one of the common fuzzy inference systems and he designed one of the first fuzzy controllers to control of system engine. Mamdani's fuzzy inference system is divided into four major steps: fuzzification, rule evaluation, aggregation of the rule outputs and defuzzification. Michio Sugeno use a singleton as a membership function of the rule consequent part. The following definition shows the Mamdani and Sugeno fuzzy rule base [22-33]

$$
\begin{aligned}
& \text { if } x \text { is } A \text { and } y \text { is } B \text { then } z \text { is C'mamdani' } \\
& \text { if } x \text { is } A \text { and } y \text { is } B \text { then } z \text { is } f(x, y) \text { 'sugeno' }
\end{aligned}
$$

When $x$ and $y$ have crisp values fuzzification calculates the membership degrees for antecedent part. Rule evaluation focuses on fuzzy operation $(A N D / O R)$ in the antecedent of the fuzzy rules. The aggregation is used to calculate the output fuzzy set and several methodologies can be used in fuzzy logic controller aggregation, namely, Max-Min aggregation, Sum-Min aggregation, Max-bounded product, Max-drastic product, Max-bounded sum, Max-algebraic sum and Min-max. Defuzzification is the last step in the fuzzy inference system which it is used to transform fuzzy set to crisp set. Consequently defuzzification's input is the aggregate output and the defuzzification's output is a crisp number. Centre of gravity method (COG) and Centre of area method (COA) are two most common defuzzification methods.
For sliding mode controller application the system performance is sensitive to the sliding surface slope coefficient $(\lambda)$. For instance, if large value of $\lambda$ is chosen the response is very fast the system is unstable and conversely, if small value of $\lambda$ is considered the response of system is very slow but system is stable. Therefore to have a good response, compute the best value sliding surface slope coefficient is very important.

Gradient descent algorithm is based on improving the input parameters by moving iteratively in the direction of the estimated gradient of the response of interest. One of the major concerns with this type of algorithm is the estimation of the gradient and its statistical properties. Naturally, the heart of gradient \{based algorithms is the technique used to estimate the gradient. Here we present the most common methods used in the simulation optimization literature. For further details the reader is referred to [12]. Gradient descent is based on the observation that if the multivariable function $F(x)$ is defined and differentiable in a neighborhood of a point $a$, then $F(x)$ decreases fastest if one goes from $a$ in the direction of the negative gradient of $F$ at , $a-\nabla F(a)$. It follows that, if

$$
b=a-\gamma \nabla F(a)
$$

for $\gamma \rightarrow 0$ a small enough number, then $F(a)<F(b)$. With this observation in mind, one starts with a guess $x_{0}$ for a local minimum of $F$, and considers the sequence $x_{0}, x_{1}, x_{2}, \ldots .$. such that

$$
\boldsymbol{X}_{n+\mathbf{1}}=\boldsymbol{X}_{\boldsymbol{n}}-\gamma_{n} \nabla F\left(X_{n}\right), \quad n \geq 0
$$

We have

$$
F\left(X_{0}\right) \geq F\left(X_{1}\right) \geq F\left(X_{2}\right), \geq \cdots
$$

\section{Gradient Descent Optimization Algoritm}


So hopefully the sequence $\left(X_{n}\right)$ converges to the desired local minimum. Note that the value of the step size $\gamma$ is allowed to change at every iteration. With certain assumptions on the function $F$ (for example, $F$ convex and $\nabla F$ Lipschitz) and particular choices of $\gamma$ (e.g., chosen via a line search that satisfies the Wolfe conditions), convergence to a local minimum can be guaranteed. When the function $F$ is convex, all local minima are also global minima, so in this case gradient descent can converge to the global solution.

\section{Results and Discussion}

Gradient descent optimal algorithm fuzzy sliding mode controller (GDA) was tested to Step response trajectory. In this simulation, to control position of continuum robot the first, second, and third joints are moved from home to final position without and with external disturbance. The simulation was implemented in MATLAB/SIMULINK environment. These systems are tested by band limited white noise with a predefined $40 \%$ of relative to the input signal amplitude. This type of noise is used to external disturbance in continuous and hybrid systems and applied to nonlinear dynamic of these controllers.

\section{GDA Sliding Mode Controller Optimization:}

In GDA fuzzy sliding mode controller; controllers performance are depended on the gain updating factor $(K)$ and sliding surface slope coefficient $(\lambda)$. These two coefficients are computed by GDA optimization; Figures 4 and 5.

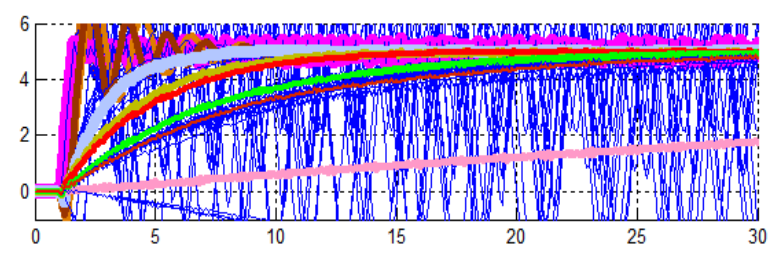

Fig. 4: Trajectory Gradient descent optimization in sliding mode controller

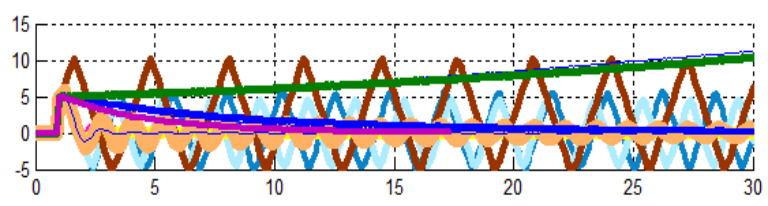

Fig. 5: Error; Gradient descent optimization in sliding mode controller

Tracking performances: In GDA fuzzy sliding mode controller; the performance is depended on the gain updating factor $(K)$ and sliding surface slope coefficient $(\lambda)$. These two coefficients are computed by gradient descent optimization. Figure 6 shows tracking performance in GDASMC and SMC without disturbance for step trajectory.
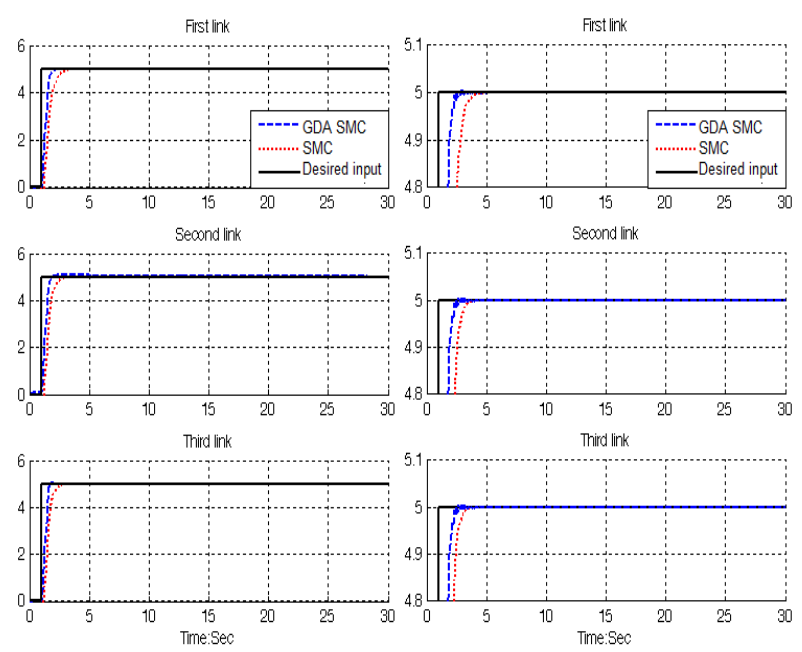

Fig. 6: Gradient descent optimal SMC vs. Trial and error SMC

Disturbance rejection: Figure 7 shows the power disturbance elimination in GDASMC and SMC with disturbance for step trajectory. The disturbance rejection is used to test the robustness comparisons of these controllers for step trajectory. A band limited white noise with predefined of $40 \%$ the power of input signal value is applied to the step trajectory. It found fairly fluctuations in trajectory responses. Based on Figure 5; by comparing step response trajectory with $40 \%$ disturbance of relative to the input signal amplitude in SMC and GDASMC, GDAFSMC's overshoot about $(0.5 \%)$ is lower than FTFSMC's $(1.2 \%)$.
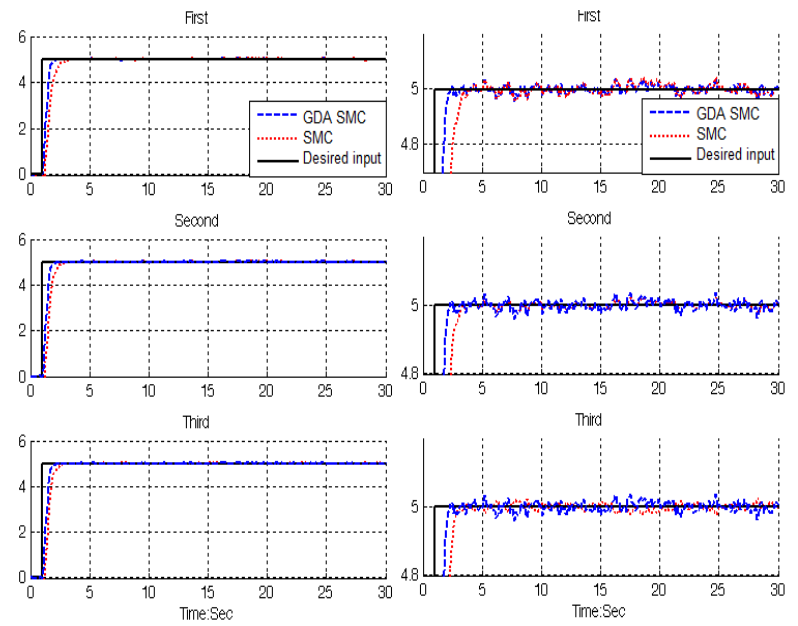

Fig. 7: Gradient descent optimal FSMC vs. SMC: in presence of $40 \%$ disturbance

Torque performance: Figure 8 and 9 have indicated the power of chattering rejection in GDASMC and SMC with $40 \%$ disturbance and without disturbance. Figure 7 shows torque performance for first three links continuum robot in GDASMC and SMC without disturbance. Based on Figure 7, GDASMC and SMC give considerable torque performance in certain system and both of controllers eliminate the chattering phenomenon in this situation. 

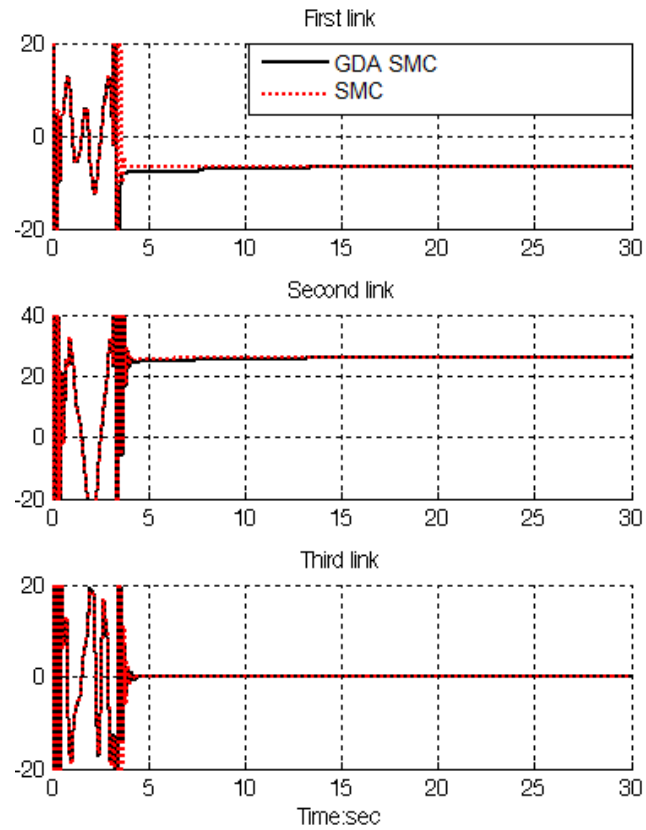

Fig. 8: Gradient descent optimal FSMC vs. SMC: Torque performance

Figure 9 has indicated the robustness in torque performance for first three links continuum robot in GDASMC and SMC in presence of $40 \%$ disturbance. Based on Figure 9, it is observed that both of two controllers have oscillation. This is mainly because pure SMC and optimal sliding mode controller are robust but they have limitation in presence of external disturbance.
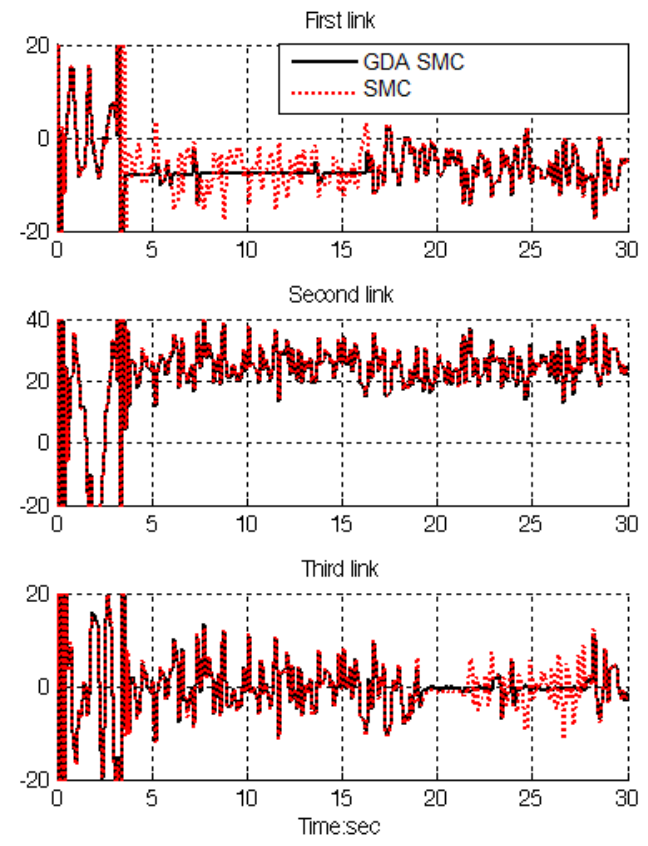

Fig. 9: Gradient descent optimal SMC vs. SMC: Torque performance with noise

The GDASMC gives significant steady state error performance when compared to SMC. When applied $40 \%$ disturbances in SMC the RMS error increased rapidly approximately $22 \%$ (percent of increase the SMC RMS error $\left.=\frac{(40 \% \text { disturbance } R M S \text { error }}{\text { no disturbanceRMS error }}=\frac{0.22 e-4}{1 e-7}=22 \%\right)$ and in GDASMC the RMS error increased approximately $9.17 \%$ (percent of increase the GDASMC RMS error $\left.=\frac{(40 \% \text { disturbance } R M S \text { error }}{\text { no disturbance } \text { RMS error }}=\frac{11 e-4}{1.2 e-6}=9.17 \%\right)$.

\section{Conclusion}

The central issues and challenges of control and estimation problems are to satisfy the desired performance objectives in the presence of noises, disturbances, parameter perturbations, unmodeled dynamics, sensor failures, actuator failures, time delays, etc. Gradient descent fuzzy sliding mode control has shown growing popularity in both industry and academia. To improve the optimality and robustness, we have proposed optimal gradient descent control for nonlinear systems with general performance criteria. Sliding mode method provides us an effective tool to control nonlinear systems through the switching function and dynamic formulation of nonlinear system. Mixed performance criteria have been used to design the controller and the relative weighting matrices of these criteria can be achieved by choosing different coefficient matrices. The optimal control can be obtained by solving gradient descent at each time. The simulation studies show that the proposed method provides a satisfactory alternative to the existing nonlinear control approaches.

\section{References}

[1] G. Robinson, and J. Davies, "Continuum robots - a state of the art,"Proc. IEEE International Conference on Robotics and Automation, Detroit, MI, 1999, vol. 4, pp. 2849-2854.

[2] I.D. Walker, D. Dawson, T. Flash, F. Grasso, R. Hanlon, B. Hochner, W.M. Kier, C. Pagano,C.D. Rahn, Q. Zhang, “Continuum Robot Arms Inspired by Cephalopods, Proceedings SPIE Conference on Unmanned Ground Vehicle Technology VII, Orlando, FL, pp 303-314, 2005.

[3] K. Suzumori, S. Iikura, and H. Tanaka, "Development of Flexible Microactuator and it's Applications to Robotic Mechanisms", Proceedings IEEE International Conference on Robotics and Automation, Sacramento, California, pp. 1622-1627, 1991.

[4] D. Trivedi, C.D. Rahn, W.M. Kier, and I.D. Walker, "Soft Robotics: Biological Inspiration, State of the Art, and Future Research", Applied Bionics and Biomechanics, 5(2), pp. 99-117, 2008.

[5] W. McMahan, M. Pritts, V. Chitrakaran, D. Dienno, M. Grissom, B. Jones, M. Csencsits, C.D. Rahn, D. Dawson, and I.D. Walker, "Field Trials 
and Testing of "OCTARM" Continuum Robots", Proc. IEEE International Conference on Robotics and Automation, pp. 2336-2341, 2006.

[6] W. McMahan, I.D. Walker, “Octopus-Inspired Grasp Synergies for Continuum Manipulators”, Proc. IEEE International Conference on Robotics and Biomimetics, pp. 945- 950, 2009.

[7] I. Boiko, L. Fridman, A. Pisano and E. Usai, "Analysis of chattering in systems with secondorder sliding modes," IEEE Transactions on Automatic Control, No. 11, vol. 52,pp. 2085-2102, 2007.

[8] J. Wang, A. Rad and P. Chan, "Indirect adaptive fuzzy sliding mode control: Part I: fuzzy switching," Fuzzy Sets and Systems, No. 1, vol. 122,pp. 21-30, 2001.

[9] J. J. E. Slotine, "Sliding controller design for nonlinear systems," International Journal of Control, No. 2, vol. 40, pp. 421-434, 1984.

[10] R. Palm, "Sliding mode fuzzy control," IEEE conference proceeding, 2002, pp. 519-526.

[11] H. Elmali and N. Olgac, "Implementation of sliding mode control with perturbation estimation (SMCPE)," Control Systems Technology, IEEE Transactions on, No. 1, vol. 4, pp. 79-85, 2002.

[12] J. Moura and N. Olgac, "A comparative study on simulations vs. experiments of SMCPE," IEEE conference proceeding, 2002, pp. 996-1000.

[13] Y. Li and Q. Xu, "Adaptive Sliding Mode Control With Perturbation Estimation and PID Sliding Surface for Motion Tracking of a Piezo-Driven Micromanipulator," Control Systems Technology, IEEE Transactions on, No. 4, vol. 18, pp. 798-810, 2010.

[14] B. Wu, Y. Dong, S. Wu, D. Xu and K. Zhao, "An integral variable structure controller with fuzzy tuning design for electro-hydraulic driving Stewart platform," IEEE conference proceeding, 2006, pp. 5-945.

[15] Farzin Piltan, N. Sulaiman, Zahra Tajpaykar, Payman Ferdosali, Mehdi Rashidi, "Design Artificial Nonlinear Robust Controller Based on CTLC and FSMC with Tunable Gain," International Journal of Robotic and Automation, 2 (3): 205-220, 2011.

[16] Farzin Piltan, A. R. Salehi and Nasri B Sulaiman.," Design artificial robust control of second order system based on adaptive fuzzy gain scheduling," world applied science journal (WASJ), 13 (5): 1085-1092, 2011.

[17] Farzin Piltan, N. Sulaiman, Atefeh Gavahian, Samira Soltani, Samaneh Roosta, "Design Mathematical Tunable Gain PID-Like Sliding Mode Fuzzy Controller with Minimum Rule Base,"
International Journal of Robotic and Automation, 2 (3): 146-156, 2011.

[18] Farzin Piltan , A. Zare, Nasri B. Sulaiman, M. H. Marhaban and R. Ramli, , "A Model Free Robust Sliding Surface Slope Adjustment in Sliding Mode Control for Robot Manipulator," World Applied Science Journal, 12 (12): 2330-2336, 2011.

[19] Farzin Piltan , A. H. Aryanfar, Nasri B. Sulaiman, M. H. Marhaban and R. Ramli "Design Adaptive Fuzzy Robust Controllers for Robot Manipulator," World Applied Science Journal, 12 (12): $2317-$ 2329, 2011.

[20] Farzin Piltan, N. Sulaiman , Arash Zargari, Mohammad Keshavarz, Ali Badri, "Design PIDLike Fuzzy Controller With Minimum Rule Base and Mathematical Proposed On-line Tunable Gain: Applied to Robot Manipulator," International Journal of Artificial intelligence and expert system, 2 (4):184-195, 2011.

[21] Farzin Piltan, Nasri Sulaiman, M. H. Marhaban and R. Ramli, "Design On-Line Tunable Gain Artificial Nonlinear Controller," Journal of Advances In Computer Research, 2 (4): 75-83, 2011.

[22] Farzin Piltan, N. Sulaiman, Payman Ferdosali, Iraj Assadi Talooki, “ Design Model Free Fuzzy Sliding Mode Control: Applied to Internal Combustion Engine," International Journal of Engineering, 5 (4):302-312, 2011.

[23] Farzin Piltan, N. Sulaiman, Samaneh Roosta, M.H. Marhaban, R. Ramli, "Design a New Sliding Mode Adaptive Hybrid Fuzzy Controller," Journal of Advanced Science \& Engineering Research , 1 (1): 115-123, 2011.

[24] Farzin Piltan, Atefe Gavahian, N. Sulaiman, M.H. Marhaban, R. Ramli, "Novel Sliding Mode Controller for robot manipulator using FPGA," Journal of Advanced Science \& Engineering Research, 1 (1): 1-22, 2011.

[25] Farzin Piltan, N. Sulaiman, A. Jalali \& F. Danesh Narouei, "Design of Model Free Adaptive Fuzzy Computed Torque Controller: Applied to Nonlinear Second Order System," International Journal of Robotics and Automation, 2 (4):232-244, 2011.

[26] Farzin Piltan, N. Sulaiman, Iraj Asadi Talooki, Payman Ferdosali, "Control of IC Engine: Design a Novel MIMO Fuzzy Backstepping Adaptive Based Fuzzy Estimator Variable Structure Control ," International Journal of Robotics and Automation, 2 (5):360-380, 2011.

[27] Farzin Piltan, N. Sulaiman, Payman Ferdosali, Mehdi Rashidi, Zahra Tajpeikar, "Adaptive MIMO Fuzzy Compensate Fuzzy Sliding Mode Algorithm: Applied to Second Order Nonlinear System," 
International Journal of Engineering, 5 (5): 380398, 2011.

[28] Farzin Piltan, N. Sulaiman, Hajar Nasiri, Sadeq Allahdadi, Mohammad A. Bairami, "Novel Robot Manipulator Adaptive Artificial Control: Design a Novel SISO Adaptive Fuzzy Sliding Algorithm Inverse Dynamic Like Method," International Journal of Engineering, 5 (5): 399-418, 2011.

[29] Farzin Piltan, N. Sulaiman, Sadeq Allahdadi, Mohammadali Dialame, Abbas Zare, "Position Control of Robot Manipulator: Design a Novel SISO Adaptive Sliding Mode Fuzzy PD Fuzzy Sliding Mode Control," International Journal of Artificial intelligence and Expert System, 2 (5):208-228, 2011.

[30] Farzin Piltan, SH. Tayebi HAGHIGHI, N. Sulaiman, Iman Nazari, Sobhan Siamak, "Artificial Control of PUMA Robot Manipulator: A-Review of Fuzzy Inference Engine And Application to Classical Controller ," International Journal of Robotics and Automation, 2 (5):401-425, 2011.

[31] Farzin Piltan, N. Sulaiman, Abbas Zare, Sadeq Allahdadi, Mohammadali Dialame, "Design Adaptive Fuzzy Inference Sliding Mode Algorithm: Applied to Robot Arm," International Journal of Robotics and Automation , 2 (5): 283-297, 2011.

[32] Farzin Piltan, Amin Jalali, N. Sulaiman, Atefeh Gavahian, Sobhan Siamak, "Novel Artificial Control of Nonlinear Uncertain System: Design a Novel Modified PSO SISO Lyapunov Based Fuzzy Sliding Mode Algorithm ," International Journal of Robotics and Automation, 2 (5): 298$316,2011$.

[33] Farzin Piltan, N. Sulaiman, Amin Jalali, Koorosh Aslansefat, "Evolutionary Design of Mathematical tunable FPGA Based MIMO Fuzzy Estimator Sliding Mode Based Lyapunov Algorithm: Applied to Robot Manipulator," International Journal of Robotics and Automation, 2 (5):317-343, 2011.

[34] Farzin Piltan, N. Sulaiman, Samaneh Roosta, Atefeh Gavahian, Samira Soltani, "Evolutionary Design of Backstepping Artificial Sliding Mode Based Position Algorithm: Applied to Robot Manipulator," International Journal of Engineering, 5 (5):419-434, 2011.

[35] Farzin Piltan, N. Sulaiman, S.Soltani, M. H. Marhaban \& R. Ramli, "An Adaptive sliding surface slope adjustment in PD Sliding Mode Fuzzy Control for Robot Manipulator," International Journal of Control and Automation , 4 (3): 65-76, 2011.

[36] Farzin Piltan, N. Sulaiman, Mehdi Rashidi, Zahra Tajpaikar, Payman Ferdosali, "Design and Implementation of Sliding Mode Algorithm:
Applied to Robot Manipulator-A Review ," International Journal of Robotics and Automation, 2 (5):265-282, 2011.

[37] Farzin Piltan, N. Sulaiman, Amin Jalali, Sobhan Siamak, and Iman Nazari, "Control of Robot Manipulator: Design a Novel Tuning MIMO Fuzzy Backstepping Adaptive Based Fuzzy Estimator Variable Structure Control ," International Journal of Control and Automation, 4 (4):91-110, 2011.

[38] Farzin Piltan, N. Sulaiman, Atefeh Gavahian, Samaneh Roosta, Samira Soltani, "On line Tuning Premise and Consequence FIS: Design Fuzzy Adaptive Fuzzy Sliding Mode Controller Based on Lyaponuv Theory," International Journal of Robotics and Automation, 2 (5):381-400, 2011.

[39] Farzin Piltan, N. Sulaiman, Samaneh Roosta, Atefeh Gavahian, Samira Soltani, "Artificial Chattering Free on-line Fuzzy Sliding Mode Algorithm for Uncertain System: Applied in Robot Manipulator," International Journal of Engineering, 5 (5):360-379, 2011.

[40] Farzin Piltan, N. Sulaiman and I.AsadiTalooki, "Evolutionary Design on-line Sliding Fuzzy Gain Scheduling Sliding Mode Algorithm: Applied to Internal Combustion Engine," International Journal of Engineering Science and Technology, 3 (10):7301-7308, 2011.

[41] Farzin Piltan, Nasri B Sulaiman, Iraj Asadi Talooki and Payman Ferdosali.," Designing On-Line Tunable Gain Fuzzy Sliding Mode Controller Using Sliding Mode Fuzzy Algorithm: Applied to Internal Combustion Engine," world applied science journal (WASJ), 15 (3): 422-428, 2011.

[42] Farzin Piltan, N. Sulaiman, M. H. Marhaban, Adel Nowzary, Mostafa Tohidian," "Design of FPGA based sliding mode controller for robot manipulator," International Journal of Robotic and Automation, 2 (3): 183-204, 2011.

[43] I. Eksin, M. Guzelkaya and S. Tokat, "Sliding surface slope adjustment in fuzzy sliding mode controller," Mediterranean Conference, 2002, pp. 160-168.

[44] Samira Soltani \& Farzin Piltan, "Design Artificial Nonlinear Controller Based on Computed Torque like Controller with Tunable Gain". World Applied Science Journal,14 (9): 1306-1312, 2011.

[45] Farzin Piltan, H. Rezaie, B. Boroomand, Arman Jahed," Design robust back stepping online tuning feedback linearization control applied to IC engine," International Journal of Advance Science and Technology, 42: 183-204, 2012.

[46] Farzin Piltan, I. Nazari, S. Siamak, P. Ferdosali ,'Methodology of FPGA-based mathematical error-based tuning sliding mode 
controller" International Journal of Control and Automation, 5(1): 89-110, 2012.

[47] Farzin Piltan, M. A. Dialame, A. Zare, A. Badri ,'Design Novel Lookup table changed Auto Tuning FSMC: Applied to Robot Manipulator" International Journal of Engineering, 6(1): 25-40, 2012.

[48] Farzin Piltan, B. Boroomand, A. Jahed, H. Rezaie, "Methodology of Mathematical ErrorBased Tuning Sliding Mode Controller" International Journal of Engineering, 6(2): 96-112, 2012.

[49] Farzin Piltan, F. Aghayari, M. R. Rashidian, M. Shamsodini, "A New Estimate Sliding Mode Fuzzy Controller for Robotic Manipulator" International Journal of Robotics and Automation, 3(1): 45-58, 2012.

[50] Farzin Piltan, M. Keshavarz, A. Badri, A. Zargari, "Design novel nonlinear controller applied to robot manipulator: design new feedback linearization fuzzy controller with minimum rule base tuning method" International Journal of Robotics and Automation, 3(1): 1-18, 2012.

[51] Piltan, F., et al. "Design sliding mode controller for robot manipulator with artificial tunable gain". Canaidian Journal of pure and applied science, 5(2), 1573-1579, 2011.

[52] Farzin Piltan, A. Hosainpour, E. Mazlomian, M.Shamsodini, M.H Yarmahmoudi. "Online Tuning Chattering Free Sliding Mode Fuzzy Control Design: Lyapunov Approach" International Journal of Robotics and Automation, 3(3):77-105, 2012.

[53]Farzin Piltan, M.H. Yarmahmoudi, M. Shamsodini, E.Mazlomian, A.Hosainpour. " PUMA-560 Robot Manipulator Position Computed Torque Control Methods Using MATLAB/SIMULINK and Their Integration into Graduate Nonlinear Control and MATLAB Courses" International Journal of Robotics and Automation, 3(3):167-191, 2012.

[54] Farzin Piltan, R. Bayat, F. Aghayari, B. Boroomand. "Design Error-Based Linear ModelFree Evaluation Performance Computed Torque Controller" International Journal of Robotics and Automation, 3(3):151-166, 2012.

[55] Farzin Piltan, S. Emamzadeh, Z. Hivand, F. Shahriyari \& Mina Mirazaei ." PUMA-560 Robot Manipulator Position Sliding Mode Control Methods Using MATLAB/SIMULINK and Their Integration into Graduate/Undergraduate Nonlinear Control, Robotics and MATLAB Courses" International Journal of Robotics and Automation, 3(3): 106-150,2012.

[56] Farzin Piltan, J. Meigolinedjad, S. Mehrara, S. Rahmdel." Evaluation Performance of $2^{\text {nd }}$ Order
Nonlinear System: Baseline Control Tunable Gain Sliding Mode Methodology" International Journal of Robotics and Automation, 3(3):192-211, 2012.

[57] Farzin Piltan, M. Mirzaie, F. Shahriyari, Iman Nazari \& S. Emamzadeh." Design Baseline Computed Torque Controller" International Journal of Engineering, 3(3):129-141, 2012.

\section{Authors' Profiles}

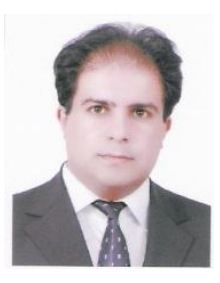

Farzin Piltan was born on 1975, Shiraz, Iran. In 2004 he is jointed the research and development company, SSP Co, Shiraz, Iran. In addition to 7 textbooks, Farzin Piltan is the main author of more than 50 scientific papers in refereed journals. $\mathrm{He}$ is editorial board of international journal of control and automation (IJCA), editorial board of International Journal of Intelligent System and Applications (IJISA), editorial board of IAES international journal of robotics and automation, editorial board of International Journal of Reconfigurable and Embedded Systems and reviewer of (CSC) international journal of robotics and automation. His main areas of research interests are nonlinear control, artificial control system and applied to FPGA, robotics and artificial nonlinear control and IC engine modelling and control.

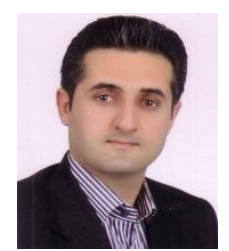

AliReza Nabaee is an electrical electronic researcher of research and development company SSP. Co. His main areas of research interests are nonlinear control, artificial control system and robotics.

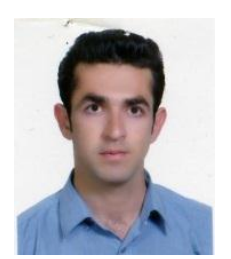

MohammadMahidi Ebrahimi is an electrical communication researcher of research and development company SSP. Co. His main areas of research interests are nonlinear control, artificial control system and robotics.

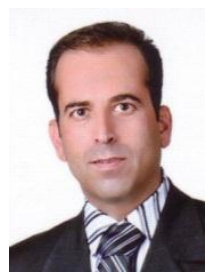

Mansour Bazregar is an industrial management researcher of research and development company SSP. Co. $\mathrm{He}$ is now pursuing his Master in industrial management. He is an expert Industrial and Quality Management in this company. His research activities deal with the IC engine control, robot control and supply chain management. 